\title{
Synthesis
}

\section{Philosophical Issues in Ecology: Recent Trends and Future Directions}

\author{
$\underline{\text { Mark Colyvan }}^{1}, \underline{\text { Stefan Linquist }}^{2}$, William Grey $^{3}{ }^{3} \underline{\text { Paul E. Griffiths }}^{1}, \underline{\text { Jay Odenbaugh }}^{4}$, and \\ Hugh P. Possingham $^{3}$
}

\begin{abstract}
Philosophy of ecology has been slow to become established as an area of philosophical interest, but it is now receiving considerable attention. This area holds great promise for the advancement of both ecology and the philosophy of science. Insights from the philosophy of science can advance ecology in a number of ways. For example, philosophy can assist with the development of improved models of ecological hypothesis testing and theory choice. Philosophy can also help ecologists understand the role and limitations of mathematical models in ecology. On the other side, philosophy of science will be advanced by having ecological case studies as part of the stock of examples. Ecological case studies can shed light on old philosophical topics as well as raise novel issues for the philosophy of science. For example, understanding theoretical terms such as "biodiversity" is important for scientific reasons, but such terms also carry political importance. Formulating appropriate definitions for such terms is thus not a purely scientific matter, and this may prompt a reevaluation of philosophical accounts of defining theoretical terms. We consider some of the topics currently receiving attention in the philosophy of ecology and other topics in need of attention. Our aim is to prompt further exchange between ecology and philosophy of science and to help set the agenda for future work in the philosophy of ecology. The topics covered include: the role of mathematical models, environmental problem formulation, biodiversity, and environmental ethics.
\end{abstract}

Key Words: biodiversity; community ecology; decision theory; environmental ethics; hypothesis testing; philosophy of ecology; population models

\section{INTRODUCTION}

A good philosophical understanding of ecology is important for a number of reasons. First, ecology is an important and fascinating branch of biology, with distinctive philosophical issues. Second, ecology is only one small step away from urgent political, ethical, and management decisions about how best to live in an apparently fragile and increasingly degraded environment. Third, properly conceived, philosophy of ecology can contribute directly to our understanding of ecology and to its advancement. Philosophy of ecology can therefore be seen as part of the emerging discipline of "biohumanities," where the disciplines of biology and humanities together advance our understanding and knowledge of biology (Stotz and Griffiths 2008). Here we focus primarily on this third role of philosophy of ecology, and consider a number of places where philosophy can contribute to ecology. We survey some of the current research being done in the area of philosophy of ecology, and we make suggestions for an agenda for future research in this area. We also hope to help clarify what philosophy of ecology is and what it should aspire to be.

We discuss several topics related to philosophy of ecology and conservation biology, starting with the role and understanding of mathematical models. This is followed by a discussion of several practical problems involving the standard model of hypothesis testing and the use of decision-theoretic methods in environmental science. We then move on to discuss the issue of how we should understand biodiversity, and why this matters for conservation management. Finally, we look at environmental ethics and its relationship with ecology and conservation biology. These four topics were chosen because they are of contemporary interest in philosophy of ecology circles and are topics where 
there is much fruitful work still to be done. The topics in question are also useful vehicles for highlighting the variety of places where philosophy might prove useful to ecology and conservation biology. These four topics were chosen because they are of contemporary interest in philosophy of ecology circles and are topics where there is much fruitful work still to be done. The topics in question are also useful vehicles for highlighting the variety of places where philosophy might prove useful to ecology and conservation biology.

\section{MATHEMATICAL MODELS IN POPULATION ECOLOGY AND CONSERVATION BIOLOGY}

There are two quite different kinds of mathematical models employed in ecology and conservation biology, and each gives rise to interesting philosophical questions about the relationship between mathematical models and the target system being modeled. We call the first kind of model a "descriptive model." Examples of descriptive models include the familiar models of singlespecies population growth, such as the logistic equation (and its more sophisticated cousins), and multi-species models such as the Lotka-Volterra predator-prey equations. Such models attempt to describe (and perhaps explain) the behavior of some aspect of the environment. There is a second kind of model that we call a "normative model." Normative models make claims about how things ought to be. They are not in the business of describing how things are, but rather they prescribe how things should be. The prime examples of normative mathematical models are formal decision models used in conservation management. Of course, in each case, there are more sophisticated models than the textbook ones we consider here, but the general points we wish to make about models also carry over to the more sophisticated ones. We therefore restrict our discussion to the simpler "toy" models.

Descriptive models will be considered first. These models make a number of idealizations about the target biological system. For example, the logistic equation assumes a constant carrying capacity and a constant growth rate, and the complications of age structure are ignored. The Lotka-Volterra equation assumes that the predator is a specialist and that capture and conversion efficiencies are constant (Gotelli 2001). Of course, there are various modifications of these models that relax these idealizations, but these modified models also carry their own idealizations, including whether the order of the governing differential equations is first order or second order (Ginzburg and Colyvan 2004). It is part of the business of modeling to introduce idealizations and simplifications. But why?

Answering this question takes us deep into important issues in the philosophy of science. Here, we will touch on some of these issues and highlight why considering the case of ecological modeling might be fruitful in exploring them. We will also discuss why the relevant philosophy of science might shed light on the scientific questions of model choice in ecology. The first (and perhaps superficial) answer as to why models must introduce idealizations is tractability. Without idealizations, a model would be mathematically and practically intractable. We obviously do not want models as complicated and as cumbersome as the systems they model. The question then arises as to how simplified models, riddled as they are with false assumptions, can tell us anything about the target systems (Cartwright 1983). This is really the crux of the matter. To provide a concrete example, how is it that assuming a constant carrying capacity can tell us anything about a population living in an environment whose carrying capacity varies? Perhaps the answer is that if the carrying capacity does not vary too much (assuming a certain amount of robustness of the model), the predictions we make from the model will not be too far from the truth. Determining when such idealizations are justified and when they are not is no easy task. It often depends on trial and error, and a great deal of good judgment on the part of the modeler.

There is another, less defensive answer to the question of how simplified models can tell us anything interesting about the target system. It might be argued that idealizations are not merely made for mathematical and practical tractability. Rather, the abstraction away from irrelevant detail might be thought to allow the model to pinpoint what makes the target system really tick (Batterman 2002). Such a philosophical take on modeling suggests that these so-called descriptive models might be explanatory as well. It seems that ecology is a particularly good place to investigate this line of thought, because population models, for example, are not usually taken to be offering explanations. 
The reasons for thinking that population models cannot be explanatory are many and we will touch on just one here. Ecology is the study of complicated biological interactions, and it would seem that any real explanation will need to deal with the biological complexity in its full detail. At least, the explanation will need to identify the relevant causal details, but these will be hard to identify. To put the point crudely, population abundance must be explained by identifying the relevant causal details of how it is that each organism is alive or dead. It would seem to have nothing to do with differential equations. But perhaps this is taking too narrow a view of the kinds of explanations ecology seeks. After all, there are other interesting ecological facts in need of explanation, such as the long-term behavior of a population as it approaches an approximatelyconstant carrying capacity. What kinds of abundance cycles will emerge and why? Will the population asymptotically approach the carrying capacity, or will it rapidly decline? The individuallevel biology seems poorly equipped to answer these more global questions. Mathematical models seem to provide exactly the right tools for this job. Moreover, if this line of argument is thought to be compelling, ecological modelers might find that there is no need to be defensive about the simple and often unrealistic assumptions of their models. At least, simple-minded, naïve criticisms of the idealizations may miss the point of what the model in question is supposed to be doing (Odenbaugh 2001, Colyvan and Ginzburg 2003, Ginzburg and Jensen 2004).

The point of the example is to help illustrate the differences between such normative models and other kinds of scientific models; nothing much hangs on the particular example chosen. We now turn to a discussion of normative mathematical models. As we have already mentioned, the standard decision-theoretic model that counsels an agent to maximize expected utility is the main example of a normative mathematical model. However, here we will discuss consensus models, which provide another example of a normative mathematical model that has recently found applications in conservation planning. The point of the example is to help illustrate the differences between such normative models and other kinds of scientific models; nothing much hangs on the particular example chosen.

There are many situations where a group, with strong differences of opinion, is charged with a conservation-management decision and must come to a consensus about what to do. There are various mathematical models that tackle the problem of group decisions, but one that has been recently applied to environmental decisions is the LehrerWagner (1981) consensus model (Regan et al. 2006, Steele et al. 2007). In essence (without going into too much detail), this model takes each group member's value for some disputed quantity, and each group member assigns "weightings of respect" to the other group members. "Weightings of respect" is a technical term, but for present purposes, it can be understood in the obvious way.) The model represents the values that each of the $n$ members of the group has for the disputed quantity as an $n$-vector and all the weightings of respect in an $n \times n$ matrix. It can then be proven that, so long as the group members do not assign trivial weightings of respect (i.e., the lowest respect to all others and maximal respect to themselves), on iteration (i.e., repeated matrix multiplication), the model delivers a consensus value for the disputed quantity. The idea is that individuals will update their view about the disputed quantity based on their respect for the expertise of others in the group.

This model is normative (rather than descriptive) because it prescribes the result that the group ought to arrive at. It does not describe the behavior of some particular group. The beauty of such a model is that once the group members have provided the model with their weightings of respect and their values for the disputed quantity, they have done all that is required of them. The model will do the work and deliver the desired result. Of course, we presuppose here that there is a certain amount of agreement about surrounding issues. If there is fundamental disagreement (about how to proceed, about how to represent various quantities, or even which quantities are relevant, for example), the model may be of limited or no use. It must be remembered, however, that we are introducing this model only as an example, so it is not unreasonable for us to assume that the conditions for its implementation are satisfied. If they are not, other methods (e.g., more general and less formal appeals to reflective equilibrium) might fare better for the problems at hand.

There are a number of idealizations in the model as presented. Some are apparently for mathematical convenience (e.g., that the weightings of respect remain constant throughout the process), whereas others are normative. It is this latter class of 
idealization that is distinctive to normative models and deserves further discussion. The normative idealizations are those that prescribe that each agent's beliefs and preferences have a certain structure, for example. The norm of coherence (beliefs obey standard probability theory), for example, is supposed to be prescriptive, rather than descriptive. Having preferences satisfy the standard axioms (e.g., that preferences be transitive: that is, if $A$ is preferred to $B$ and $B$ is preferred to $C$ then $A$ should also be preferred to $C$ ) is again prescriptive. These idealizations are often said to capture the structure of the beliefs and preferences of an ideally rational agent. There are undoubtedly agents whose beliefs and preferences do not conform to these axioms, but such agents are thought to be defective in some way. Arguably, such agents are irrational and ought to reform their beliefs and preferences so as to satisfy the relevant axioms. These idealizations are quite different from other idealizations in science, precisely because of their normative character. Indeed, there seems to be no analog of such idealizations in other (non-normative) scientific models. (For example, it is not as though predators really ought to be specialists or that carrying capacity ought to be constant. Such assumptions play completely different roles in the relevant models.)

There is a great deal of interest in the normative idealizations we have mentioned. Perhaps the most interesting feature of these normative models involves the interaction of the normative idealizations with those introduced for mathematical convenience. For instance, we might agree that a normative theory of belief (such as Bayesian belief theory) compels us to at least strive toward having our beliefs satisfy the axioms of probability theory. To do otherwise is to sin against rationality, or so this line of thought goes. To change the example, however, what about agents in a consensus situation who wish to change their respect weightings as a result of disagreements over the disputed quantity? This hardly seems irrational, and yet the model depends on this assumption. Our point here is that although the models under discussion are normative, not every assumption is normative. This in turn casts some doubt on the normative force of the results delivered by these models. Given that formal models (of which the consensus model is only one example) have great potential in conservation management, a better understanding of both kinds of idealization would constitute a major advance for ecology and conservation biology. Moreover, few other branches of science offer such an opportunity to study the interactions of these quite distinct kinds of idealization.

\section{PROBLEMS WITH ENVIRONMENTAL PROBLEM FORMULATION}

Two issues of genuinely practical concern to ecologists and conservation biologists involve the standard model of hypothesis testing and the implementation of formal decision methods in conservation planning. Both of these issues offer opportunities for the philosophy of ecology to engage with ecology itself. We will discuss each of these issues in turn.

The standard scientific model of hypothesis testing involves testing the hypothesis in question (the alternative hypothesis) against the null hypothesis. The model places the burden of proof on rejecting the null hypothesis. That is, very often the experiment (or survey) fails to reject the null hypothesis, yet the alternative hypothesis is clearly true. For example, a survey may fail to demonstrate that land clearing results in a reduction in the number of bird species in the area in question (Martin and Possingham 2005, Hilborn and Mangel 1997). However, this failure is often an artifact of the model of hypothesis testing employed. Standard hypothesis testing is very conservative, in that it guards against false positives (type I errors). But sometimes in science, false negatives are more worrying. Believing that no extinctions are occurring or that land clearing is having no impact on the number of bird species, for example, can be very dangerous null hypotheses to fail to reject.

A better model of hypothesis testing in ecology and conservation biology is required here. There has been a great deal of work on such issues from the fields of both philosophy and ecology. This work includes critiques of the standard hypothesis tests along with the development of Bayesian (McCarthy 2007) and other models that allow various alternative hypotheses to be tested against one another. However, the philosophical work has yet to find its way into mainstream ecology (although see Fidler et al. 2006, and the references therein). There is a genuine need here for interdisciplinary work (in philosophy, statistics, and ecology) to present the critiques of the standard model of hypothesis testing and to present some of the alternatives to the ecology community. There is also 
the more practical problem of retraining working ecologists in alternative statistical techniques and hypothesis testing, as well as ensuring that the new methods are useful in practice. Such practical work would seem to offer another fruitful locus of interaction between philosophers (especially those with more applied interests) and ecologists.

The second issue for discussion is the application of decision theory to conservation planning. The central idea of decision theory is that an agent ought to choose the act that maximizes his or her own expected utility. This advice is based on the insight that it is expectations that matter, rather than utilities on their own, or probabilities on their own. The idea can be illustrated with an example from conservation biology. It may well be that it is best to focus conservation efforts on species other than those in greatest danger of extinction. Critically endangered species have a high probability of extinction in the near future, and depending on the details, may well go extinct, regardless of conservation efforts to save them. Endangered and threatened species, on the other hand, may respond better to conservation efforts and we might get better value for our conservation dollars by focusing attention on them. This "triage" approach has a great deal to recommend it, and yet most conservation efforts focus on the most endangered species (Possingham 2001, Field et al. 2004, Wilson et al. 2006).

The example in the preceding paragraph is not meant to advance or endorse any general rule about where conservation efforts should be focused. Rather, it is just a warning that a great deal of conservation management may well be flying in the face of decision theory. However, the devil is in the details, and it is important to assess each case on its merits. This involves becoming very clear about the goal of any conservation intervention and its probability of success. Spelling out clear objectives and specifying how success will be measured are crucial steps. This attention to detail is something forced by the use of formal models of decision, and it is one of the great benefits of using such models. They do not allow one to embark on management strategies without goals and without a clear definition of success.

Although we are in general agreement with such a decision-theoretic approach to conservation efforts, there are nonetheless some interesting social, political, and ethical issues that arise. For a start, decision theory does not easily incorporate ethical sensibilities (although see Colyvan et al., in press). For instance, it might be maintained that certain ethical considerations are nonnegotiable. If so, this is difficult to accommodate in the decision-theoretic approach, where everything is negotiable (at least in principle) through a cost-benefit analysis. This relates to more practical, political reasons for resisting the decision-theoretic approach. It might be easier to motivate concern for the environment based on ethical considerations. Moreover, advocating environmental triage might encourage a kind of environmental complacency whereby individuals fail to concern themselves with looming potential environmental disasters (such as global warming) that they see as inevitable. This complacency may impede efforts to slow greenhouse-gas emissions and may even make things worse. Although it is not always possible to deal with the worst cases, public attention to, and sympathy with, such cases may well increase the public's receptiveness to, and participation in, environmental efforts elsewhere.

These are complex issues residing on the boundary of conservation management and ecology. They are certainly issues that deserve more discussion than we can provide here. But very briefly, there are a number of useful tools for dealing with these more complicated situations. These methods (most notably, game-theoretic methods) force consideration about reactions (from both other agents and the environment) to decisions made. In light of such reactions, the initially tempting decision might not survive as the best alternative. Thinking in such terms also helps guard against an overemphasis on short-term benefits when decisions have long-term consequences. At present, game-theoretic methods are underused in conservation biology, and yet they seem to hold great promise for dealing with at least some of the issues we raised for standard decision theory (Colyvan and Steele, in press).

The decision-theoretic way of looking at environmental decisions also has ramifications for determining how much ecological monitoring is worthwhile. There is a standard application of decision theory for the assessment of the value of information, i.e., how much should be paid for new information. Such decision-theoretic assessments of monitoring practices are rare in environmental management. If such assessments were carried out, it may well turn out that some of the current monitoring work would fail to be worthwhile 
(Taylor and Gerrodette 1993, Field et al. 2004). Again, this is an area where philosophy can help. Although decision theory and optimization methods are already in circulation in conservation management circles, it is fair to say that the uptake of these methods is slow. Work from philosophicaldecision theorists providing justification and motivation for the use of formal decision methods in such settings may well help the rate of uptake and thus improve the quality of conservation management decisions.

\section{BIODIVERSITY}

Biodiversity has historically been defined as the number of species and their respective abundances in a given region (Ghilarov 1996). However, many conservationists consider this definition inadequate, and several attempts have been made to expand the concept to include a wider range of biological entities and processes (Holt 2006). One popular definition equates biodiversity with the total diversity in genes, species, and communities in a region. Another proposal includes diversity in habitat structure and function to this list (Noss 1990). Yet another version equates biodiversity with the total amount of taxonomic diversity above the species level (Faith 1994). It is generally agreed that none of these definitions can accommodate the diverse range of management and assessment goals in biodiversity-oriented conservation biology. However, there is no general theoretical framework for assessing how well (or poorly) particular accounts of biodiversity are suited to specific conservation or scientific aims. In this section, we identify a philosophical distinction between two different applications of the biodiversity concept. These two applications are biodiversity considered as an index, and biodiversity considered as an end. We illustrate how each application places different constraints on how biodiversity is defined (Maclaurin and Sterelny 2008).

Biodiversity is sometimes used as an index or gauge for some other property of interest. For example, biodiversity is sometimes regarded as an index of a community's long-term stability, or as an index of the quality of ecosystem services provided by a region (e.g., nutrient cycling or carbon storage), or as an index of a region's potential for providing medicinal or industrial products. This view of biodiversity as an index of something valuable should not be confused with the concept of a biodiversity surrogate. A biodiversity surrogate is some practical measurement strategy for estimating the amount of biodiversity in a region. For example, counting the number of amphibian species in a region might be a reliable surrogate for its total biodiversity (Heyer et al. 1994).

The second way of conceptualizing biodiversity is not as an index of something valuable, but rather as an end or value in itself (Calicott 1997). There is a long-standing tradition in conservation biology of viewing biodiversity as an "intrinsic" good (Soul\&eacute 1985, Calicott 1997). According to this view, to say that one region is more biodiverse than another region implies that, all things being equal, the first region is a higher conservation priority than the second, regardless of any links between biodiversity and other properties of interest. When the concept of biodiversity is employed in this fashion, it is being used as a normative (value-laden) concept. In contrast, when biodiversity is considered as an index, it is being used in an empirical (or non-value-laden) sense. Each application raises a different set of issues. Regarding biodiversity as an index raises various scientific questions about the causal relationship between biodiversity and the property of interest. However, regarding biodiversity as an end raises a variety of ethical questions about the ultimate source of this value (see below) and how to balance the value of biodiversity against other social and economic goods. Within the biodiversity literature, there is a tendency to conflate these two applications of the biodiversity concept. In the remainder of this section, we briefly illustrate how different conceptions of biodiversity are suited to these two forms of assessment.

The adequacy of a given biodiversity index depends on which property one is interested in promoting. Community stability, ecosystem services, or medicinal properties are each likely to be indexed by some forms of biodiversity and not others. For example, biodiversity may be valued because it potentially offers medicinal benefits. In this case, taxonomic diversity above the species level is a good biodiversity index. Taxonomically disparate species are more likely to contain nonoverlapping medicinal proteins than close relatives (Faith 1994). In contrast, if biodiversity is valued because it promotes ecological stability, then taxonomic diversity above the species level is potentially a poor index of biodiversity. Assuming that the redundancy model of the diversity-stability 
relationship is accurate, the reason why more diverse communities are more stable is because they contain a greater number of species with overlapping functional roles. As a general rule, closely related species will overlap more extensively in "niche breadth" than more distantly related ones. For example, two species of hymenoptera are more likely to perform similar ecosystem functions (e.g., pollination) than a given species of hymenopteran and a mammal. Therefore, according to this model, preserving taxonomic diversity above the species level is a poor strategy for promoting ecosystem stability, as it is unlikely to conserve closely related species with overlapping functional roles.

Our current aim is not to defend the details of these proposals, but rather to illustrate a general point about the appropriateness of different biodiversity indices for different ends. There is no single concept of biodiversity that serves as a reliable index for all ecological properties of value. This fact suggests a form of biodiversity pluralism, where the definition of biodiversity employed depends on the objectives being promoted. But this is certainly not an "anything goes" form of pluralism. A considerable amount of theoretical and empirical work is required to identify the potentially valuable properties in various ecological systems and to determine which forms of biodiversity are the most reliable indices for each of those properties.

As we have noted, a distinct set of issues arise when evaluating biodiversity as a normative concept. Here too, different conceptions of biodiversity will be more or less appropriate, depending on which ethical theory is endorsed. The above discussion has touched on some of the philosophical and scientific issues surrounding the concept of biodiversity. We have not mentioned the debate over how to choose biodiversity surrogates. Nor have we considered whether biodiversity comparisons can be made on a global scale, or whether they are necessarily regional. In addressing these further issues, however, it will be helpful to keep the two senses of "biodiversity" in mind. Scientific questions about the reliability of different forms of biodiversity as indices for various different ecological values should be distinguished from ethical questions about the value of biodiversity as an end in itself.

\section{ENVIRONMENTAL ETHICS}

A basic guiding intuition behind much work in conservation biology is that the biological world contains a great deal of value and that this is threatened by human activities. Furthermore, the suggestion is that we may need to modify our behavior if we are to avoid massively impoverishing our world. Environmental ethics emerged as a result of concern about a perceived degradation of the natural world. In developing principles for protecting biodiversity and promoting the health of ecosystems, environmental philosophers have generally assumed that the conceptual framework for describing the natural world (e.g., "species," "biodiversity") is unproblematic. However, as we have already seen, the notion of "biodiversity," at least, is problematic, and arguably, similar problems can be raised in relation to other relevant biological terms.

Another widely shared assumption of environmental philosophy is that because the causes of environmental problems are (or appear to be) largely anthropogenic, a fundamental source of these problems is anthropocentrism. (Anthropocentrism can be defined as the view that the value of an object or state of affairs is determined exclusively in terms of its value to human beings.) Rejecting anthropocentrism has been almost a sine qua non of environmental ethics. Indeed, biocentric, ecocentric, and deep ecology treatises often begin with alleged refutations of anthropocentrism. A common thread that unites these positions is the concern to provide some rationale for the claim that nonhuman biological entities (from bacteria to plants to entire ecological communities) merit the same consideration that is typically extended only to humans. Thus, many environmental philosophers and conservation biologists alike have traditionally defended some version of the idea that all biological entities are "intrinsically valuable", that is, that biological entities have a moral standing or value that is independent of human values and concerns (McCauley 2006, Sagoff 2008).

However, the necessity, and even the possibility, of a genuinely nonanthropocentric ethic has been challenged (e.g., Grey 1993, 1998, Justus et al. 2009). First, nonanthropocentrism suffers epistemological problems. How do we come to know these nonanthropocentric values and how do we rank them (as we must if we are to make environmental management decisions)? Second, nonanthropocentrism 
is not genuinely motivating. Deep ecology preaches to the choir, and even then, it does so only to that portion of the choir who are believers in intrinsic value. (We recognize that motivating people to respect moral constraints is a foundational problem, and it is not entirely clear that the problem is any more serious in the case of nonanthropocentric environmental values.) Third, anthropocentrism leads to a loss of bearings in moral space. The nonanthropocentric or ecocentric candidates for the basis of ecological value, such as biodiversity, do not tell us which biodiverse biotas we should prefer. To do that, we need anthropocentrism, which tells us that we should prefer the biodiverse biotas that are best for us (Grey 1993).

An example will help to illustrate the shortcomings of intrinsic approaches to value. A primary environmental concern is the (alleged) current mass extinction of species due to human interference in the natural environment. Any adequate environmental ethic should identify this state of affairs as undesirable. However, a truly "deep" ecology ethic that eschews anthropocentric values altogether provides no basis for regarding mass extinction as bad or objectionable. If paleontology teaches us anything about mass-extinction events, it teaches us that such events are usually followed by major biological radiations. Just as the removal of reptiles as the dominant life form on Earth made way for the radiation of mammals, so too would the current mass extinction make way for a different set of organisms to flourish and eventually dominate the planet. From a purely nonanthropocentric perspective, there is no reason to value the current set of organisms found on Earth over some other group. Granted, it might take millions of years for this radiation to occur. But from a nonanthropocentric perspective, a million years is not such a long time (considering that life on Earth has flourished for several billion years). Thus, the value of preserving most species currently found on Earth is grounded in an anthropocentric time frame and in anthropocentric values. The problem with genuinely nonanthropocentric theories of value is that they do not provide us with any way of ordering states of the world as better and worse. To do this, these theories of values must be fortified with a measure of anthropocentrism (Grey 1993, 1998).

It is also worth noting that it is a mistake to consider environmental ethics in isolation from the relevant ecology. Indeed, this is one of the reasons that philosophy of ecology is so interesting: ecology lies tantalizingly close to important ethical issues. To claim that we need to act on environmental concerns requires knowledge about the state of the natural world, and we turn to ecology and conservation biology, in particular, for empirical support for many claims about the seriousness of environmental problems. There are also difficult epistemological and conceptual issues in conservation biology and ecology (some of which we have already considered), and these too need to be dealt with along with the ethical issues. A satisfactory normative framework to guide our environmental choices, which is the ambition of environmental ethics, requires a solid basis of biological knowledge, as well as a good philosophical understanding of the biology and the concepts it employs.

A great deal of effort in environmental ethics has been expended in trying to expand the circle of moral concern to include natural entities. The circle has been variously extended to conscious beings, sentient beings, living beings, and even to all existing things. Most of these attempts fail, because, for example, they fail to value species (giving preference to individuals), they generate the problem of value attenuation, and they create intractable problems for priority setting. Singer's (1975) animal-welfare approach is problematic because it seems to lead to sentience chauvinism; it does not pay due respect to nonsentient organisms. Of course, we need to be careful here. The failure of existing arguments for widening our circle of moral concern need not be a reason for rejecting the position altogether, just for rejecting these considerations as providing the basis for the sole source of value. For example, we might allow pluralism about these wider circles of interest, valuing sentient and nonsentient organisms, individuals, and species, etc. But it is fair to say that any attempt to found conservation efforts on such (nonanthropocentric) widening of the circle of moral concern needs further development. The anthropocentric view does not seem to suffer such problems, because according to this view, we humans are more or less free to value what we like, which can include species, individuals (sentient or not), and even rocks and nonliving things if we are so disposed. However, the liberalism of anthropocentrism comes at a price. Its major problem is a direct result of its permissiveness. Unconstrained anthropocentrism leaves us free to value too much. For example, it does not prohibit us valuing impoverished environments, polluted 
industrial sites, degraded agricultural land, and the like.

Although most of these ethical issues have received a great deal of attention, there are other issues that remain underexplored. These are issues concerning the relationship between environmental ethics and the relevant science. As we have already noted, the importance of science to environmental ethics is clear. Perhaps it is less obvious that environmental ethics can help inform ecology. One way that this can occur is that if particular features of the environment are seen to be the bearers of environmental value (or are the features of the environment that it is appropriate for us to value), then this would hopefully prompt further research into the features in question. Think of the attention given to measuring biodiversity. This is at least in part due to the important role biodiversity is supposed to play in debates in environmental ethics. Or suppose that deep ecology and its insistence on intrinsic environmental values is misguided. What would this mean for conservation management? It would make the operations research and triage approaches to environmental decision making less controversial. After all, from this perspective, the value of the environment is to be understood in instrumental terms. It is understood to be the value for us, for some well-defined purpose. Related to this is an issue (touched on above) about reconciling ethics and decision theory. Recognizing value is one thing, but charting courses of action to preserve the things of value involves accommodating uncertainty. More specifically, we should pursue those courses of action that perform best on some balance of value and success. This takes us beyond the realm of ethics and into decision theory and scientific treatments of uncertainty. Much work has yet to be done on this topic (Colyvan and Steele, in press), yet a satisfactory reconciliation of ethics and decision theory is essential for informed and productive conservation decisions.

\section{THE FUTURE OF PHILOSOPHY OF ECOLOGY}

The above topics are typical of some of the interesting work currently being pursued in environmental philosophy, but there are also many others. Some of these other topics include the complexity-stability hypothesis (May 1973, Pimm 1984), the issue of how to deal with the various kinds of uncertainty encountered in ecology (Regan et al.
2001, 2002), issues surrounding community ecology (Leopold 1968, Whittaker 1975, Sterelny 2006), the ethical and policy implications of biobanking and carbon offsetting (Bekessy et al., in press), the question of what ecosystem stability amounts to (Mikkelson 1999, Odenbaugh 2007, Justus 2008), and other interesting issues and questions (Peters 1991, Haila and Levins 1992, Shrader-Frechette and McCoy 1993, Pickett et al. 1994, Sterelny and Griffiths 1999, Cooper 2003, Sarkar 2005, Anderies and Norberg 2008, Colyvan 2008). The topics we have discussed above, along with the others just mentioned, all appear to be ones where fruitful interaction between ecologists and philosophers of ecology is either already occurring or will occur in the near future. There are still only a handful of philosophers who would count philosophy of ecology among their areas of expertise, let alone see it as their primary research interest. But the philosophical issues in ecology and conservation biology are far too interesting to remain so relatively unexplored. Moreover, the potential to make a real difference to conservation efforts is a major incentive. We hope that our writing will help draw attention to some of the topics to be found at the intersection of philosophy and ecology, and to demonstrate how these two disciplines can be of service to one another.

Responses to this article can be read online at: http://www.ecologyandsociety.org/voll4/iss2/art22/ responses/

\section{Acknowledgments:}

This paper is a product of the Second Queensland Biohumanities conference held in June 2006 in Brisbane, Australia. This conference was devoted to the philosophy of ecology and included all of the authors on this paper as participants or speakers. The authors would like to thank those who attended this interdisciplinary conference for their contributions and for the very lively discussion following each presentation. We are particularly indebted to Greg Cooper, Hamish McCallum, Greg Mikkelson, Katie Steele, and John Wilkins. Mark Colyvan is grateful to Lev Ginzburg and Gimme Walter for many interesting conversations on some of the topics covered by this paper. Work on this project was supported by an Australia Research Council Federation Fellowship to Paul Griffiths 
(FF0457917), by an Australia Research Council Discovery Grant to Mark Colyvan (DP0879681), by the Australian Centre of Excellence for Risk Analysis, and the Commonwealth Environment Research Facilities Research Hub: Applied Environmental Decision Analysis.

\section{LITERATURE CITED}

Anderies, J. M., and Norberg, J. 2008. Theoretical challenges: information processing and navigation in social-ecological systems. Pages 155-179 in J. Norberg and G. Cumming, editors. Complexity theory for a sustainable future. Columbia University Press, New York, New York, USA.

Batterman, R. W. 2002. Asymptotics and the role of minimal models. British Journal for the Philosophy of Science 53(1):21-38.

Bekessy, S. A., B. A. Wintle, M. Colyvan, B. Langford, D. B. Lindenmayer, and H. P. Possingham. In press. The biodiversity bank cannot be a lending bank. Environmental Economics.

Calicott, J. B. 1997. Values and ethics in conservation. Pages 29-56 in G. K. Meffe and C. R. Carroll, editors. Principles of conservation biology. Second edition. Sinauer, Sunderland, Massachusetts, USA.

Cartwright N. 1983. How the laws of physics lie. Clarendon, Oxford, UK.

Colyvan, M. 2008. Population ecology. Pages 301320 in S. Sarkar and A. Plutynski, editors. A Companion to the philosophy of biology. Blackwell, Oxford, UK.

Colyvan, M., and L. R. Ginzburg. 2003. The Galilean turn in population ecology. Biology and Philosophy 18(3):401-414.

Colyvan, M., D. Cox, and K. Steele. In press. Modelling the moral dimension of decisions. Noûs.

Colyvan, M., and K. Steele. In press. Environmental ethics and decision theory: fellow travellers or bitter enemies? In B. Brown, K. de Laplante, and K. Peacock, editors. Handbook of the philosophy of science volume 11: philosophy of ecology. North Holland/Elsevier, Amsterdam, Netherlands.

Cooper, G. J. 2003. The science of the struggle for existence: on the foundations of ecology. Cambridge University Press, Cambridge, UK.

Faith, D. P. 1994. Phylogenetic pattern and the quantification of organismal biodiversity. Philosophical Transactions of the Royal Society: Biological Sciences 345:45-58.

Fidler, F., M. A. Burgman, G. Cumming, R. Buttrose, and N. Thomason. 2006. Impact of criticism of null-hypothesis significance testing on statistical reporting practices in conservation biology. Conservation Biology 20(5):1539-1544.

Field, S. A., A. J. Tyre, N. Jonzén, J. R. Rhodes, and H. P. Possingham. 2004. Minimizing the cost of environmental management decisions by optimizing statistical thresholds. Ecological Letters 7:669-675.

Ghilarov, A. 1996. What does "biodiversity" mean? Scientific problem or convenient myth? Trends in Ecology and Evolution 11(7):304-306.

Ginzburg, L. R., and M. Colyvan. 2004. Ecological orbits: how planets move and populations grow. Oxford University Press, New York, New York, USA.

Ginzburg, L. R., and C. X. J. Jensen. 2004. Rules of thumb for judging ecological theories. Trends in Ecology and Evolution 19(3):121-126.

Gotelli, N. J. 2001. A primer of ecology. Third edition. Sinauer, Sunderland, Massachusetts, USA.

Grey, W. 1993. Anthropocentrism and deep ecology. Australasian Journal of Philosophy. 71:463-475.

Grey, W. 1998. Environmental value and anthropocentrism. Ethics and the Environment. 3 (1):97-103.

Haila, Y., and R. Levins. 1992. Humanity and nature: ecology, science and society. Pluto, London, UK.

Heyer, W. R., M. A. Donnelly, R. W. McDiarmid, 
L.A. C. Hayek, and M.S. Foster. 1994. Measuring and monitoring biological diversity: standard methods for amphibians. Smithsonian Institution Press, Washington, D.C., USA.

Hilborn, R., and M. Mangel. 1997. The ecological detective. Princeton University Press, Princeton, New Jersey, USA.

Holt, A. 2006. Biodiversity definitions vary within the discipline. Nature 444(7116): 146.

Justus, J. 2008. Ecological and Lyapunov stability. Philosophy of Science 75(4):421-436.

Justus, J., M. Colyvan, H. M. Regan, and L. A. Maguire. 2009. Buying into conservation: intrinsic versus instrumental value. Trends in Ecology and Evolution 24(4):187-191.

Lehrer, K., and C. Wagner. 1981. Rational consensus in science and society. Reidel, Dordrecht, Germany.

Leopold, A. 1968. A sand county almanac. Oxford University Press, New York, New York, USA.

Maclaurin, J., and K. Sterelny. 2008. What is biodiversity? Chicago University Press, Chicago, Illinois, USA.

Martin, T. G., and H. P. Possingham. 2005. Predicting the impact of livestock grazing on birds using foraging height data. Journal of Applied Ecology 42:400-408.

May, R. M. 1973. Stability and complexity in model ecosystems. Princeton University Press, Princeton, New Jersey, USA.

McCarthy, M. A. 2007. Bayesian methods for ecology. Cambridge University Press, Cambridge, UK.

McCauley, D. J. 2006. Selling out on nature. Nature 443(7107):27-28.

Mikkelson, G. M. 1999. Methods and metaphors in community ecology: the problem of defining stability. Perspectives on Science 5:481-498.

Noss, R. F. 1990. Indicators for monitoring biodiversity: a hierarchical approach. Conservation Biology 4(4):355-364.
Odenbaugh, J. 2001. Ecology, stability, model building and environmental policy: a reply to some of the pessimism. Philosophy of Science 68:S493S505.

Odenbaugh, J. 2007. Seeing the forest and the trees. Philosophy of Science 74(5):628-641.

Peters, R. H. 1991. A critique for ecology. Cambridge University Press, Cambridge, UK.

Pickett, S. T. A., J. Kolasa, and C. G. Jones. 1994. Ecological understanding: the nature of theory and the theory of nature. Academic Press, San Diego, California, USA.

Pimm S. L. 1984. The complexity and stability of ecosystems. Nature 307(5949):321-326.

Possingham, H. P. 2001. The business of biodiversity: applying decision theory principles to nature conservation. Tela 9:1-37.

Regan, H. M., M. Colyvan, and M. A. Burgman. 2002. A taxonomy and treatment of uncertainty for ecology and conservation biology. Ecological Applications 12(2):618-628.

Regan, H. M., M. Colyvan, and L. MarkovchickNicholls. 2006. A formal model for consensus and negotiation in environmental management. Journal of Environmental Management 80(2):167-176.

Regan, H. M., R. Lupia, A. N. Drinnan, and M. A. Burgman. 2001. The currency and tempo of extinction. The American Naturalist 157(1):1-10.

Sagoff, M. 2008. The economy of the earth: philosophy, law, and the environment. Second edition. Cambridge University Press, Cambridge, UK.

Sarkar, S. 2005. Biodiversity and environmental philosophy. Cambridge University Press, Cambridge, UK.

Shrader-Frechette, K.S., and E. D. McCoy. 1993. Methods in ecology: strategies for conservation. Cambridge University Press, Cambridge, UK.

Singer, P. 1975. Animal liberation: a new ethics for our treatment of animals. Random House, New York, New York, USA. 
Soulé, M. E. 1985. What is conservation biology? BioScience 35(11):727-734.

Steele, K., H. M. Regan, M. Colyvan, and M. A. Burgman. 2007. Right decisions or happy decision makers? Social Epistemology 21(4):349-368.

Sterelny, K. 2006. Local ecological communities. Philosophy of Science 73:215-231.

Sterelny, K., and P. E. Griffiths. 1999. Sex and death: an introduction to the philosophy of biology. University of Chicago Press, Chicago, Illinois, USA.

Stotz, K., and P. E. Griffiths. 2008. Biohumanities: rethinking the relationship between bioscience, philosophy and history of science, and society. Quarterly Review of Biology 83(1):37-45.

Taylor, B., and T. Gerrodette. 1993. The uses of statistical power in conservation biology: the vaquita and northern spotted owl. Conservation Biology 7:489-500.

Whittaker, R. 1975. Communities and ecosystems. Second edition. MacMillan, New York, New York, USA.

Wilson, K. A., M. F. McBride, M. Bode, and H. P. Possingham. 2006. Prioritizing global conservation efforts. Nature 440(7082):337-338. 